\title{
Politique
}

Politique

\section{Alain G. Gagnon, Développement régional, État et groupes populaires, Hull, éd. Asticou, 1985, 286 p.}

\section{Denis Perreault}

Numéro 8, automne 1985

Innovations et politiques technologiques

URI : https://id.erudit.org/iderudit/040506ar

DOI : https://doi.org/10.7202/040506ar

Aller au sommaire du numéro

Éditeur(s)

Société québécoise de science politique

ISSN

0711-608X (imprimé)

1918-6584 (numérique)

Découvrir la revue

Citer ce compte rendu

Perreault, D. (1985). Compte rendu de [Alain G. Gagnon, Développement régional, État et groupes populaires, Hull, éd. Asticou, 1985, 286 p.] Politique, (8), 163-165. https://doi.org/10.7202/040506ar d'utilisation que vous pouvez consulter en ligne.

https://apropos.erudit.org/fr/usagers/politique-dutilisation/ 
Alain G. Gagnon, Développement régional, État et groupes populaires, Hull, éd. Asticou, 1985, 286 p.

La contribution sur le développement régional vue à travers les rapports entre l'État, les élites locales et les groupes populaires que nous propose Alain-G. Gagnon ne manque pas de pertinence, surtout en période de questionnement du développement, conséquence de la crise structurelle que traverse le système.

L'auteur, à partir d'instruments théoriques issus de l'approche centre-périphérie, qu'il qualifie de socio-économique, jumelé à l'approche psycho-sociale de «l'appauvrissement relatif et d'attentes grandissantes» qu'il sous-utilise, fort heureusement d'ailleurs, est amené à préciser le développement inégal que subissent les régions «périphériques» québécoises par rapport au centre Montréal/Québec.

Cette sous-utilisation théorique est heureuse en ce qu'elle permet à l'auteur d'éviter la lourdeur du débat concernant l'apport de la conceptualisation «centre-périphérie» et son postulat sousentendu «d'échange inégal». Cette conceptualisation construite pour analyser des rapports inter-étatiques et des ensembles géographiques qualifiés de dominants, dominés, est ici appliqués au développement régional québécois où l'inégalité n'a aucune commune mesure avec les réalités pour lesquelles elle a été élaboré. Plus, certaines régions "périphériques» du Québec possèdent des avantages salariaux, des conditions de travail comparables sinon plus avantageuses que celles fournies dans le «centre». Ce transfert théorique quoique très didactique camoufle et minimise l'hétérogénéité des situations et un certain regain économique pour une grande partie des régions dites "périphériques».

L'intérêt de l'ouvrage se situe beaucoup plus au niveau du portrait du cadre régional du Québec dans son ensemble et celui de l'Est du Québec en particulier. À l'intérieur de ce tableau, Gagnon esquisse les différentes conceptions rattachées au développement régional mais aussi et surtout à l'intégration, désin- 
tégration de ces zones à l'économie capitaliste en expansion insérée dans sa logique de productivité/rentabilité. Pour ce qui est de la région de l'est du Québec, région privilégiée dans l'analyse par l'auteur, ce sont surtout les secteurs de base que sont la pêche, l'agriculture et la forêt qui sont touchés. Cette logique moderniste ou la mobilité des facteurs s'est opposée à l'idée de développement diversifié, innovateur, à la création d'emploi pour absorber les surplus de main-d'œuvre.

D'après l'auteur les interventions ont cherché à atteindre trois objectifs majeurs: «l'élimination de la petite propriété, la prolétarisation de la population et la mise en disponibilité de cette population en vue de la création de centres industriels» (120).

L'auteur dégage deux visions du développement, l'une incarnée par l'État et ses officiers «technico-bureaucratiques» et l'autre par les groupes populaires. Ces deux visions sont temporisées, médiatisées par les élites locales traditionnelles lesquelles sont tantôt en accord tantôt en opposition d'intérêt avec l'une ou l'autre vision. Ce sont sur ces bases que vont se tisser des rapports de force où le modernisme technocratique du centre évoluera avec succès. Mais comme le suggère l'auteur on doit relativiser cette constatation et tenir compte de trois dimensions dans l'analyse: du politique, de l'économique et du social. Ces trois dimensions tissent des rapports complexes où les gains peuvent se départager selon les rapports de lutte mais aussi et surtout selon la conjoncture. À titre d'exemple en période pré-électorale, le comportement électoraliste des élus permet à certaines élites et groupes populaires de faire des gains souvent appréciables.

Au delà de ces mi-succès, les groupes populaires possèdent une marge de manœuvre très mince, car selon l'auteur les moyens financiers dont ils disposent sont tributaires des subventions étatiques. Là où les intérêts ont convergé, en partie du moins, les groupes communautaires ont pu élaborer une forme de dévelop- 
pement dynamique de type coopératif. Mais même à ce chapitre ce développement selon les intérêts populaires reste empreint de contradictions et de tensions importantes. Ils sont guettés par le danger de récupération "étant donné que les pouvoirs en place s'efforcent de les intégrer à leur politiques» (173).

Malgré ce danger l'auteur considère qu'il faut souligner «le caractère novateur» de ces types d'expériences cherchant à établir les bases d'un nouveau projet de société» (153).

Ce travail de synthèse considérable par l'ampleur, la profondeur de l'analyse et le sérieux des travaux et recherches dépouillés nous apporte un éclairage, une «contribution importante dans l'effort de compréhension de la mosaïque régionale du Québec» comme l'a écrit Fernand Harvey dans la préface de l'ouvrage.

Denis Perreault U.Q.A.M. 